\title{
Conceptualising megacities and megaslums in Lagos, Nigeria
}

\section{Authors:}

Olayinka Akanle

Gbenga S. Adejare ${ }^{1}$

\section{Affiliations:}

${ }^{1}$ Department of Sociology,

University of Ibadan, Nigeria

Corresponding author:

Olayinka Akanle,

yakanle@yahoo.com

Dates:

Received: 19 Jan. 2017

Accepted: 20 July 2017

Published: 28 Sept. 2017

How to cite this article:

Akanle, O. \& Adejare, G.S.,

2017, 'Conceptualising

megacities and megaslums in

Lagos, Nigeria', Africa's Public

Service Delivery and

Performance Review 5(1),

a155. https://doi.org/

10.4102/apsdpr.v5i1.155

\section{Copyright:}

(C) 2017. The Authors.

Licensee: AOSIS. This work

is licensed under the

Creative Commons

Attribution License.
Read online:
Burgeoning megacities is one of the fascinating realities of the 21st century global development. A huge chunk of individuals across the cosmos continue to crave for expansion of megacity space. Thus, living in a megacity is nothing short of psychosocial nirvana of many in the 21st century. With the growing appetite for increase in the number of megacities emanates issues of conterminous slumhood, gentrification, poverty, increasing crime rate and general hazards for lives and property. It is pertinent not to view megacity as an isolated phenomenon without considering its indelible flipside - megaslum. This article is devoted to intense analysis of pros and cons of the emergence of megacities using secondary data that were analysed in a triangulated manner. Pictorial data further complemented both theoretical and statistical information related in the work. Thus, using Lagos as an example, this article engaged the use of sociological imagination to x-ray how survival of megacities depends on a number of factors without which megacity becomes unsustainable. It is from this standpoint that the authors made useful recommendations to stakeholders in order to make Lagos megacity, and the likes, sustainable.

\section{Introduction}

The dawn of the 21st century is accompanied with an upsurge in the quest of people to live in city centres (Agbola \& Agunbiade 2009; UN Habitat 2013). There is an ever increasing demand for more cities in the 21st century than ever before in the history of humans (UN Habitat 2013). More shocking is the fact that, according to UN, about 1 billion of urban dwellers in the world have their abodes in slums without necessary infrastructural amenities like serviceable roads, pipeborne water, efficient communication system and educational system, among others (UN Habitat 2013). Empirical data (Ilesanmi 2010) demonstrate that there were over 100 slums in Lagos as at 2006 and that $70 \%$ of the total population in the city lives in slums. A little introspection into the historical fact about the origin of slums is perhaps cogent.

The Western Industrial Revolution and French Revolution of the late 19th century gave impetus to social thinkers to make enquiry into the complex social relations that were typical with the development of urban centres as well as the new social formation that is characterised by urbanism. While most epistemological accounts in urban study trace the origin of urbanisation to the late 18th-century social changes in Europe (Davis 1955), a counter view offers that there had been diverse urban-related concerns in the ancient African societies and some parts of the Arab world (Ilesanmi 2010; Kito 2012; Otite \& Ogionwo 2006). This fact was further reiterated in the etymology of urban sociology by the word Al-Umran sociology. This word was first used by the Arabian named Ibn Khaldun in the 14th century (Otite \& Ogionwo 2006; Ritzer \& Stepnisky 2014). The controversial debate with regard to how urbanisation or urbanism started is an unending one; this work is not devoted to this aspect either.

Nigeria has a unique history of urbanisation. Before the advent of colonialism, which gained fullfledged prominence in the late 19th century, the country had some flourishing cities, kingdoms, empires and towns that can be likened to the modern-day urban centres (Makinde 2012). Some of these included the Sokoto Caliphate, the Old Oyo Empire, the Benin Kingdom and the Nupe Kingdom, to mention but a few. Conversely, however, these towns and cities are somewhat different from the modern-day megacities in that they did not bring about huge social inequality. Civilisation became directly linked with living in the city or working in the industry rather than farmlands (Otite \& Ogionwo 2006). This development brought about massive rural-urban migration, especially by the youths who abandoned 'crude' farming occupation in search of jobs in the growing industries. One of the major outcomes of the disappointment was failure to secure a gainful employment in the city, which brought about the proliferation of slums (Bawaba 2014; Jayaram 2010; Makinde 2012). The momentum for deciphering the nexus of issues woven around city life was paradoxically sustained by entrepreneurial spirit for survival and innovation, the 
commercialisation of strength and housing inadequacies as a result of the inability to hire accommodation owing to its cost. Kingsley Davis (1955) in his work on 'The Origin and Growth of Urbanisation in the World' put the main reason of sociological enquiry with regard to urbanisation into four categories:

1. Urbanisation is a relatively recent phenomenon in human history. The intention here is to compare societies based on language, religion, politics, stratification and infinitum among others.

2. Urbanism shows a complete change in patterns of social system. To David, urbanism and urbanisation are but a product of advancement in economic and technological advancement.

3. Established urban centres are the epicentre of power and influence throughout the whole society. In other words, urban centres serve as the fulcrum around which relatively all activity of humans, the rich and the poor alike, now pivot.

4. The process of urbanisation is still occurring. This is a truism in the sense that there is increasing demand for more urban areas even as rural areas fade away.

Given the above stance, it thus becomes crystal clear why city study is not only important but also an eclectic one. In other words, the urgency of policy intervention in the running of urban life became imminent as a result of the social upheavals that urbanisation process engendered. The main focus of this article, being megacity and megaslum, to which due attention will now be given, is an integral part of the social conditions that evolved as a result of urbanisation and its consequences.

\section{Theoretical explanations}

There are a number of theoretical explanations advanced to reify the conceptual issues associated with spatial demarcations and social differentiations within the ambit of urban sociology. Some of these theories are examined below.

\section{Urban ecology and Marxian analyses of urban space}

This theory was developed by scholars in a Chicago school in the 1920s. Human ecology is used interchangeably with urban ecology. The main fulcrum of this theory is on the principle of biological science that explains population distribution in city space. According to this theory (urban ecology), groups occupy natural areas or neighbourhoods. A very good example of this strand of ecological theory is that of Ernest Burgess's famous concentric zones models (Anthony 2004). This model shows that cities are now increasingly arranged in the other of individual functionality and work relations in lieu of the central business district (CBD). The concentric rings have the transition zone next to the CBD, followed by the low-class zone (suitable for the working-class), next to this is the residential zone for the middle class and then the commuters' zone being the last (Anthony 2004). This model lucidly gives a clear-cut distinction between the haves and the have-nots in the society, a phenomenon the Marxists refer to as social inequality. The Marxist theorist Henri Lefebvre, a French scholar, is often credited as the forerunner of Marxian analyses on the city space. According to him, it is not so much about expansion in population or movement of people but rather the products of the actions of certain bourgeois class who control the sequence of events in the urban space (Ritzer \& Stepnisky 2014).

Lefebvre (1974/1991) insisted that that there is a chain of production and reproduction agency in terms of the social, economic, political and geographical compositions within urban centres such that inequalities at all levels are maintained. Thus, the created and maintained inequalities are constantly reified in many forms - the urban layouts, essentially. These layouts also extend to the rhythm of work life on the street. Lefebvre (1974/1991) in his work on The Production of Space gave a Marxian explanation that there is, more often than not, a capitalist domination of space. He went further to give a historical account that early pastoral societies did not dominate space. For instance, practice of land tenor system and bush fallow precluded domination of space in the pastoral age. People lived by the demand placed on them by the geography. This, according to Lefebvre, changed with the development of absolute space, which is shaped by religious and political concerns. The second category is historical space, which is believed to give way to abstract space. Abstract space is the most germane in this discursive piece. According to Lefebvre, the abstract space is produced by the modern, capitalist, industrial society. Here, the nature is dominated by human forces in the society (Anthony 2004; Ritzer \& Stepnisky 2014)

In a similar Marxian framework, dependency theory, to whit world system theory (WST), of which Immanuel Wallerstein is especially prominent, is entwined, gave another explanation for the emergence of slums in megacities. According to this theory (WST), the history of the world is that of domination such that the haves dominate the havenots, the periphery countries are dependent on core countries for capital and have underdeveloped industry. Dependency here connotes weakness on the part of one and strength on the part of the other in a symbiotic relationship. How this relates to the explanation of the emergence of megaslums is that megaslums do not exist on their own - they are produced by the complex social situations that characterise megacities.

In bringing the above theories to bear, it thus becomes crystal clear that the two polemical approaches of ecological explanation of the Chicago school and the Marxian theories of megacity-megaslum are instructive, especially with reference to the Nigerian situation. Unlike the functionalistoriented ecological explanation, the Marxian theory gives a political economy dimension (Ritzer \& Stepnisky 2014).

\section{Methodology}

This work largely benefited from secondary data. Existing statistics, pictures and literature were technically deployed to 
give a lucid in-depth representation of the subject matter of megacities and slums within the ambit of interpretive content analysis. The rationale for this methodology hinges on the need to gain flexibility for relating reflexive social and ontological realities of bourgeoning megacities and their corresponding slums. Pictorial data were used to further enhance abstract and numerical data. Data interpretation and analysis emanated from textual and contextual descriptive interpretation of findings.

\section{Megacity}

In order to fully conceptualise megacity, let us suffice it appropriate to decipher what a city is first. What then is a city? Similar to this question would be an attempt to decipher how city spaces become a possibility. City, as a concept, has varying subjective dimensions in terms of definition based on the interest and purpose of the definer. A lay definition of city suggests a social space that is the direct opposite of rural setting. Elsewhere, the city space has been conceived in terms of economic, social, financial and political relevance bequeathed on a place by government authority or popular recognition of such relevance. Essentially, progress in industries, communication systems, transportation, recreation and politics, among other things, has constantly stimulated a speedy transformation of rural centres to cities. As commerce and level of literacy improve, people receive further stimulus to define fulfilment within the context of urbanisation - this is simply because, more often than not, the city does not only serve as the hub of innovation, residence in the city also indicates a boost to individuals' social status. Be that as it may, these processes are engendered by the appropriation of rural surpluses in terms of conversion of rural wealth to urban beauty. In other words, the smart lives, brilliancy, economic buoyancy and other sophistications and aesthetics in urban spaces would not mean so much without a corresponding peripheral rural spaces lending credence to them. Thus, the city space is made possible by conscious and unconscious creative activities of the people, which cannot be severed from rural creations.

Cities vary in size, economy, resources, ecological impacts and other structural forms. A city can be, for example, small, medium, big or mega. Relevant studies show that 'small urban centres' is made up of at least 500000 dwellers, medium or moderately big cities comprise a population hovering between 1 million and 5 million residents, while megacities have a population of at least 10 million people (United Nations Economic Commission for Latin America and the Caribbean 2012). The UN data also show that there is an increasing trend in the number of people living in cities while the number of those living in rural areas continues to dwindle. As at 2014, it was estimated that about 54 percentage $\%$ of people all over the world were residing in one city or another (United Nations Department of Economic and Social Affairs, Population Division 2014).

The concept of megacity has been depicted by the United Nations as a metropolitan area with a total population in excess of 10 million people (United Nations World Economic and Social Survey 2013). Liminal conception of megacity suggests conurbation. As at 2010, there were only 25 megacities in the world (Makinde 2012). As at 2014, the number of megacities rose to 28 (Makinde 2012). Africa's megacities include Lagos in Nigeria, Cairo (Al-Qahirah) in Egypt and the last being Kinshasa in the Democratic Republic of Congo. Tokyo is the largest city space in the world with an estimated population of 38 million people (Makinde 2012). In Table 1, the megacities in Africa with their respective populations are represented.

\section{Lagos city}

Banana Island, Victoria Island, Ikoyi, Lekki, Victoria Garden City and some parts of Festac Town are desired havens of the rich in Lagos metropolis (see Figures 1, 2 and 3). Ikeja, Oshodi, CMS, Auto-Part and Aspander are industrial areas in Lagos. It is often difficult to ascertain the status of various individuals but at the close of the day's work, people return to their various homes - either ghetto or city. It is important to state here that the majority of the workforce in Lagos city are drawn from the contiguous slums in the city (Bawaba 2014; Davis 2006; Ilesanmi 2010). More to this is the fact that modern technologies, good roads and other social amenities are mainly found in the city centres at the expense of the slums. The deplorable network, eratic power supplies and traffic to slum areas after $4 \mathrm{o}^{\prime}$ clock brings about enormous stress and fatigues of slum dwellers, for example in Ajegunle and Isheri.

The essential characteristics of urbanism are the way people dress, where and what they eat, where they live and their interaction in the city. Paradoxically, there exists only a thin line between the stress level of those who dwell in Lagos city and the adjacent slums. Figures 1-3 show snapshots of desirable urban centres in Lagos.

\section{Megaslums}

It is pertinent here to define the concept of slum. A slum area refers to any area and dwellings predominated by dilapidation, overcrowding, inadequate building management and design systems, poor or lack of ventilation, insufficient sanitation facilities and poor space management, all or some of which constitute hazards to healthy living of the people (Davis 2006). Other terms used to denote slums include blighted areas, low-income areas, renewal arenas and ghettos, among others. Megaslums, according to Davis in his book The Planet of Slums, emerge as shanty-towns and squatter communities that merge in continuous belts of informal housing and poverty, usually on the urban periphery (Davis 2006). A very good example of megaslum is that of contiguous low-income housing facilities

TABLE 1: African megacity populations (in thousands) and their growth rate (2010-2015).

\begin{tabular}{lllccc}
\hline Rank & Country & City & 2010 & 2015 & $\begin{array}{c}\text { Growth rate } \\
\text { (2010-2015) }\end{array}$ \\
\hline 1 & D/R Congo & Kinshasa & 10668 & 12788 & $3.9 \%$ \\
2 & Nigeria & Lagos & 10578 & 12427 & $3.22 \%$ \\
3 & Egypt & Al-Qahirah (Cairo) & 11001 & 11663 & $1.17 \%$ \\
\hline
\end{tabular}

Source: 2012/2013 UN HABITAT (Modified) 


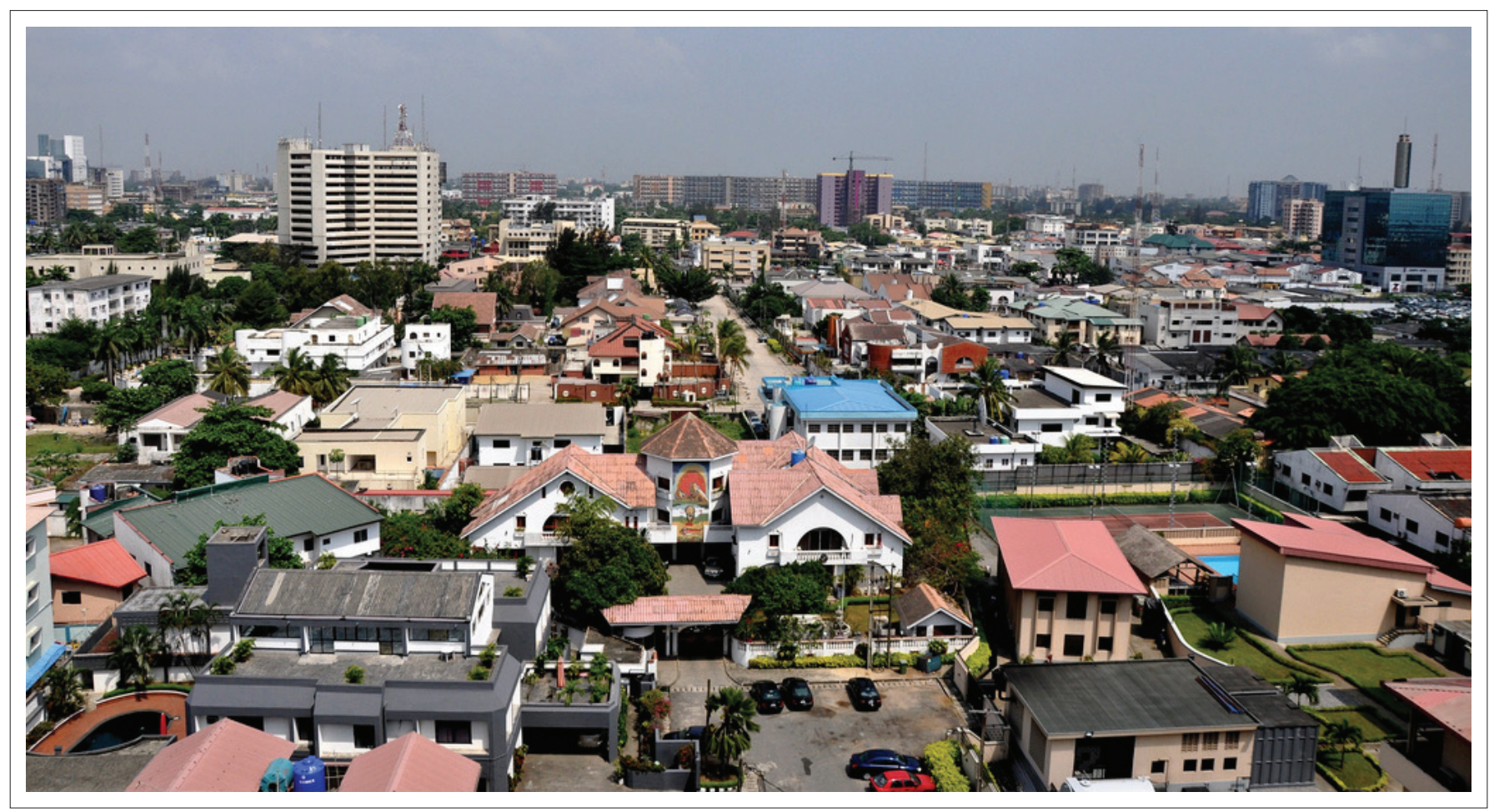

Source: Google images

FIGURE 1: Lagos Victoria Island.

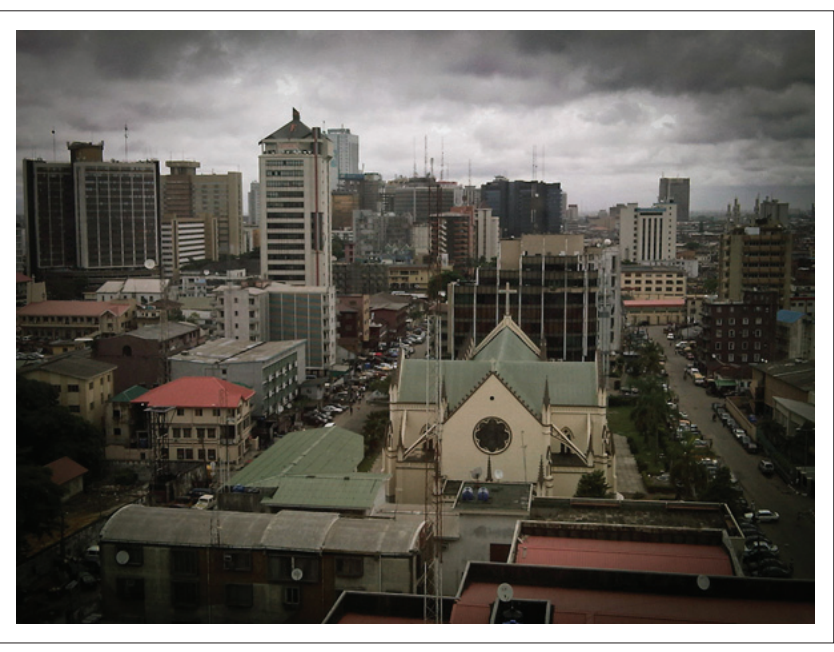

Source: Google images

FIGURE 2: Lagos Island.

in Mexico, whose population was estimated at about 6.6 million as at 1992 (Davis 2006).

Although it has been argued that there is no slum in Nigeria that could be said to possess the attribute of megaslum, Ajegunle in Lagos has been identified by Davis to possess the similitude of megaslum. More so, Ajegunle has an estimated population of about 90000 occupying 8 square kilometres of swampy land as at 1972 with over 1.5 million residents on a slightly larger space (Davis 2006). The contrast between affluence and poverty in Lagos city has been described by Ilesanmi (2010) when he observed that the history of Lagos in the last two decades of the 20th century has been marked by severe deterioration in the quality of life: high level of poverty,

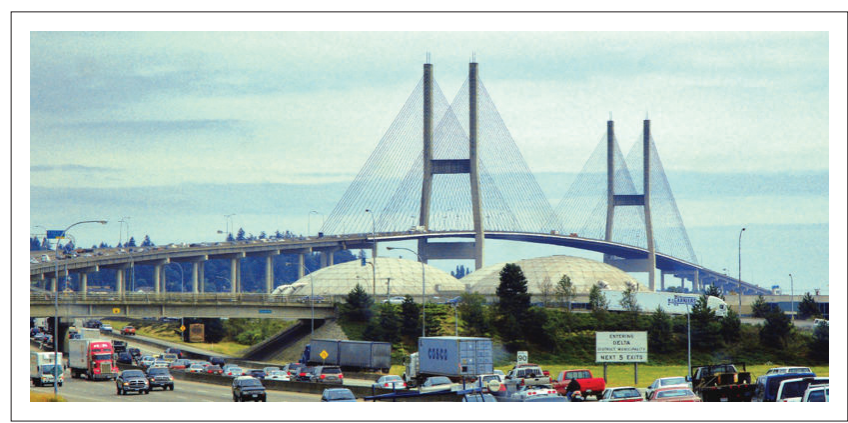

Source: Google images

FIGURE 3: A snapshot of the New Lekki-lkoyi Cable Bridge in Lagos.

proliferation of slums, environmental degradation, dilapidated and congested road system, massive flooding, disrupted sewerage network and increasing crime rates.

Largely, the communities that live in urban slums belong to the class of low-income households who migrate to cities in expectation or search for better future. They live in slums to be close to work opportunities which in many cases tend to be exploitative and informal or sometimes criminal. Some of the causes of evolution of slum include but are not limited to

(1) absence of serviced land, (2) rural-urban migration, (3) advancement in transportation and communication technologies, (4) government policy and (5) tenure system. Cyclical social change in city life is generally a very good incentive to the emergence of slums in the urban social space.

\section{Why slums?}

Pocket and linear slums exist throughout virtually all the cities of the world, including Lagos, only with few 
exceptions. In fact, all megacities in the world have slums. Lagos alone is estimated to have nothing less than 100 slums, with 2 out of every 3 Lagosians living in slums (IRIN 2006). Although what constitutes slums vary according to cities and their peculiarities, a typical slum is depicted as possessing the following attributes:

1. Poor or complete absence of basic infrastructure such as good road, electricity, good water and planned environment, among others.

2. Temporary, dilapidated or poor houses resulting from poor planning and system of approval, if any.

3. Overcrowding, high population density and congestion also result from either poor space management or insufficient space for building. In some cases, a room is used for different purposes like cooking, dining, sleeping and even for commercial purposes.

4. High tendency for deviant behaviour such as prostitution, criminal acts, bunkering, illicit sexuality, drug abuse, beggary and juvenile delinquencies, among others. The existing structures, experts believe, create a conducive atmosphere for such behaviour to thrive.

5. Because of poor integration of slum dwellers into the mainstream urban life, it is believed that resentments, apathy and isolation characterise slum areas. In other words, slums are often ignored in the urban development process because slum dwellers are seen as an inferior set of people (IRIN 2006).

As earlier indicated, rural-urban migration, more often than not, breeds misery and unnatural exclusionary treatment. Those who move from rural areas in search of better living conditions in city spaces usually fail to give proper thought to possible challenges that could emanate from this action ab initio. The consequence of this, rather rash, action has implications for many things - it affects the migrants, their family members, the departed and the receiving areas. In Nigeria, for instance, those whose migrate from rural areas often give the non-migrant members of their family a positive impression that moving onto city spaces comes with abundant fortunes. When these migrants are eventually confronted with the realities of urban complexities, resorting to slums becomes inevitable. Another unfortunate aspect of this occurrence is the socio-demographic dimension and influence of the migration: the young population are the most trapped population in this migratory trend. Agricultural activities now suffer a great neglect by the youths in Nigeria who see such agriculture as unbefitting activities left for ageing members of the society. The contradiction, that is, leaving rural areas for city centre, amounts to abandoning wealth for scarcity, especially in the face of poor preparation for such transition. Emergence of slum has also been linked to three essential forces:

- Demographic dynamism: this has to do with attraction of more people from the rural to urban areas through offering of greater potential for employment.

- Incapacity of city space to meet the rising demand for housing.
- Land policies that restrict the poor from having access to urban land. These policies are often controlled by the law of demand and supply (www.sociologyguide.com).

The emergent issues in the creation of both urban centres and their correspondent slum spaces are usually enormous. This is true in the sense that problems generated from the emergence of slums are fast becoming a global issue as they affect not only those living in slums but also the entire human race. Table 2 shows the geographical distribution of urban slum populations and their respective percentage across different regions of the world in two years - 2010 and 2012.

\section{Lagos slums}

In sharp contrast to the social, ecological or environmental, political and economic terrain in urban Lagos, the slums in Lagos depict the contradictions inherent in unequal capitalist interrelationships between the rich and the poor in symbiotic relationships. Below are some of the pictures of some slums in Lagos (see Figures 4-8).

\section{The Ghetto culture}

The culture of slum dwellers can be said to be both resilient and dynamic. It is resilient in the sense that the communal cohesion among the people of the slum makes innovation

TABLE 2: Urban slum population and their proportion across regions for 2010 and 2012.

\begin{tabular}{lcccc}
\hline Region & $\mathbf{2 0 1 0}(\mathbf{\prime} \mathbf{0 0 0})$ & $\mathbf{2 0 1 0}(\mathbf{\%})$ & $\mathbf{2 0 1 2}(\mathbf{\prime} \mathbf{0 0 0})$ & $\mathbf{2 0 1 2}(\mathbf{\%})$ \\
\hline Developing regions & 819969 & 32.6 & 862569 & 32.7 \\
Northern Africa & 11463 & 13.3 & 12226 & 13.3 \\
Sub-Saharan Africa & 198168 & 61.7 & 213134 & 61.7 \\
$\begin{array}{l}\text { Latin America and } \\
\text { the Caribbean }\end{array}$ & 110194 & 23.5 & 113424 & 23.5 \\
Eastern Asia & 197529 & 28.2 & 206515 & 28.2 \\
Southern Asia & 190647 & 35.0 & 200510 & 35.0 \\
South-eastern Asia & 76540 & 31.0 & 79945 & 31.0 \\
Western Asia & 34112 & 24.6 & 35704 & 24.6 \\
Oceania & 552 & 24.1 & 575 & 24.1 \\
\hline
\end{tabular}

Source: 2012/2013 UN HABITAT (Modified)

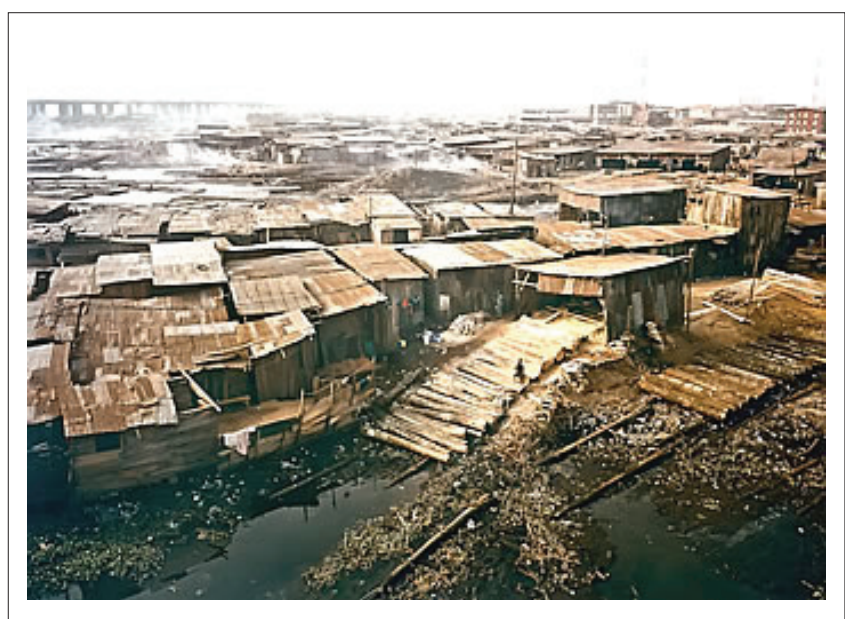

Source: Google images.

FIGURE 4: Ebuta Meta slum in Lagos 


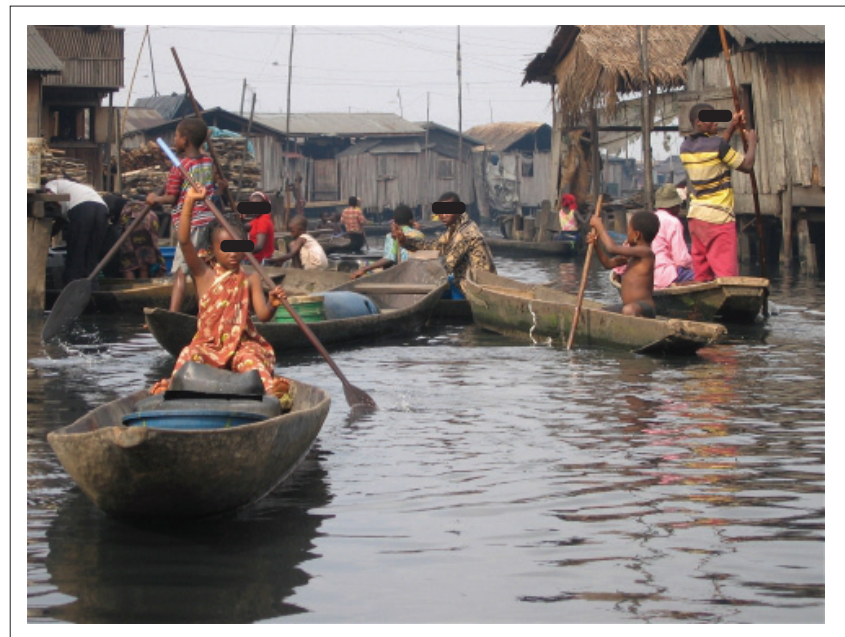

Source: Sarah Simpson/IRIN

FIGURE 5: Makoko, an example of slum of houses on stilts in central Lagos, Nigeria.

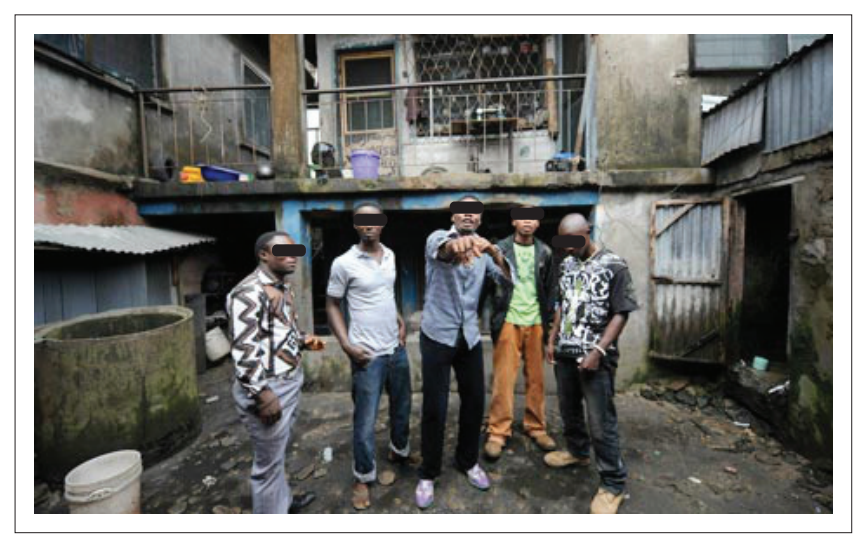

Source: Google Image

FIGURE 6: Emerging Ghetto musicians in Lagos.

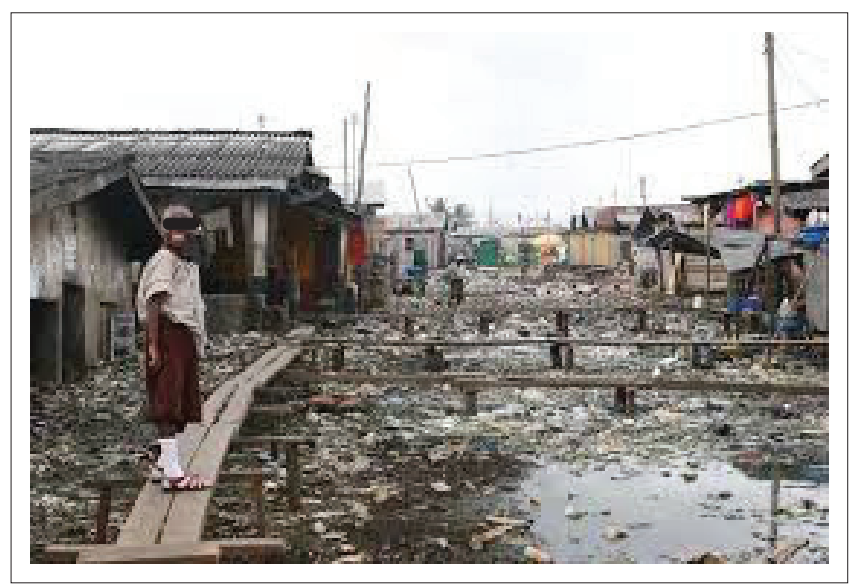

Source: Google Image

FIGURE 7: Wooden pedestrian bridge in Ajegunle Lagos.

and lasting togetherness while on the other hand, as they mingle with their counterparts in the city, they are prone and susceptible to modern trends, especially through government policies. Ironically, the slum dwellers have over the years evolved certain sub-cultures, which they are not just identified with but which are also promoted to the larger society through music and other social acts. The 2008 'Slum

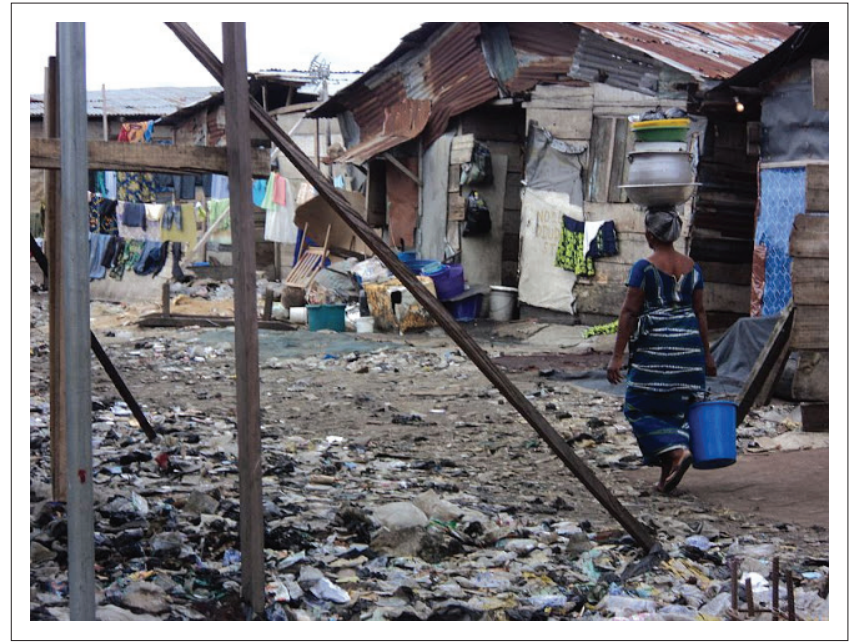

Source: Goole Image

FIGURE 8: Part of Ajegunle, an emerging megaslum in Lagos.

Dog Millionnaire' and 'Omo Ghetto' of 2010 are two films that gave a very good frictional but acurate representation of the subculture of slums in India and Nigeria, respectively.

Oritse Femi, a pop musician, and Daddy Showkey, who started their musical careers from Ajegunle, an emerging megaslum, are typical of those who help to promote the ghetto culture. Daddy Showkey specifically in one of his musical records said 'if see my mama, Hosanna, tell am sey o.... I dey for ghetto.... I no getti problem'. By implication, in can be deduced from the musical excerpt that there is a culture or way of life associated with slum life (Davis 2006; Lavasani 2013; Portes 1972). 'Nice' and Olamide of Bariga (emerging megaslum) are some of the prominent Nigerian musicians who have translated the resilience in the Lagos slums to fame and wealth. Ajegunle has also produced prominent soccer stars like Taribo West, Emmanuel Amunike and Samson Siasia as well as many Nollywood actors and actresses.

In the view of Oscar Lewis, in his 1966 classical work titled 'The Culture of Poverty', the culture exhibited by the slum dwellers typifies abject poverty and thus calls for attention and help. Conversely, however, a critical analysis of the culture of the slums dwellers, especially those in Lagos megacity, will reveal, beyond the prescient of facade of poverty, a resilient, dogged and hardworking people who are ready to eke out their lives in spite of their seeming challenge a phenomenon similar to David McClelland's need for achievement (N-Arch's). Figures 4-7 illustrate the resilience in typical Lagos slums.

\section{Further discussions}

There are a whole lot of issues associated with megacity and megaslum as a discursive piece. Given the characteristics of megaslums, it is evident that the living condition and health of slum dwellers are not in any way something to write home about. Their living condition poses a threat to health, security and the general well-being of all the people across the globe, 
and hence its global concern. Depending on their peculiarity, the lives of slum dwellers may be threatened by drought, flood, industrial gaseous emission (as in the case of many slums in Lagos) and toxic industrial wastes as well as indoor pollution. Another big challenge associated with slum life is that of unclear tenure of land: many of the slum dwellers live in land or property owned by government or private individuals in informal tenure. Interestingly, megacities are implicated by the prevailing situations in their respective slums. Thus, the need to have a holistic approach to foster development in both areas is not negotiable. Given below are some of the factors to consider in tackling the inherent socioeconomic challenges bedevilling megacities and slums alike.

\section{Government policy}

Government plays a very vital role in the regulation and construction of urban life. The policies of government can either be progressive or retrogressive depending on their implication on the lives of the people and development of the entire society. In responding to the various challenges associated with megaslums, government often resort to certain policies that are mainly categorised by the World Bank (2013) into the following:

1. Forced evictions: This entails large-scale slum demolition without any alternative option to the population displaced. This is a common practice in Nigeria among different strata of government who do this on the basis of urban renewal. This situation leads to social, psychological and emotional sickness among the displaced person. Record has it that not less than 5 million people suffer from this problem annually (World Bank 2013).

2. Clearance and relocation: This has to do with removal of slum residents from central city to resettlement sites (e.g. Kubwua in Abuja) that are usually miles away from urban areas. Once the land has been cleared out, the land is slated for development into high-value uses. The evacuated settlers are confronted with the challenge of job scarcity in their new location which forces them to return to the city as squatters.

3. Clearance and on-site redevelopment: This is an actionoriented policy of government which makes for temporary movement of the slum dwellers to rebuild the place for them. This, however, is fraught with the problem of how the moved settlers can secure temporary accommodation prior to their return, assuming they would even have the opportunity to return in the Nigerian context.

4. Upgrading: Of the four responses to megaslum challenges, this seems to be the most preferred and most humane. It consists of improving on the existing infrastructure and facilities up to a satisfactory standard.

\section{Rural-urban migration}

The influx of people from relatively less industrial cities, for instance, Ibadan, Ife and Akure, to a more industry-dense area like Lagos, more often than not, leads to city congestion. When this situation arises, society tends to degenerate to what the social Darwinists term as survival of the fittest. As against the prior illusions of urban surplus and splendour, the reality in urban centres often leaves the new immigrants at a loss, perplexed or sometimes helpless. Some of them become destitute of shelters and other basic needs. Hence, boroughs and shanties become their new home (see Aworemi, Abdul-Azeez \& Opoolo 2011; Bawaba 2014).

\section{Urban traffic congestion}

Heavy road traffic is not an abnormal phenomenon in city spaces. Traffic congestion results from a shoot up in the number of users of roads. This condition is characterised by delays in the movement of people who commute as well as the transportation of goods and services. In a megacity like Lagos, it is not abnormal for people to do morning devotion, eat breakfast or dinner and engage in other activities to cool down the stress of traffic congestion. In reality, traffic congestions make journeys longer and vehicles slower than they really are. This not only makes public transportation cumbersome but also tells on people's efficiency and health. It also has policy implication for urban dwellers as government in a bid to ease this problem has become overburdened, a condition that often calls for special interventions. Some of the interventionist policies put in place in Lagos over time includes institution of traffic control agencies. The Lagos State Traffic Management Agency is typical of these agencies. In order to avoid traffic congestions in Lagos, people leave for work very early in the morning and may not return until very late in the night. Similarly, several governments in Lagos have had to and still intervene by introducing buses for transportation to meet the everincreasing needs of the consumers. While the state of traffic congestion in Lagos is worrisome, and the demand for city transportation is increasing, there is nothing close to the experiences of megacity dwellers in places like Tokyo, Cairo or Mexico. For instance, more than 30 million people in Mexico commute daily with only about $16 \%$ using private transportation. A major contributor to this problem is absence of good road network, especially in Lagos. Simply put, stress in transportation, until reversed, is a constant attribute of city life in Lagos just as it is in almost all megacities around the world.

\section{Urban gentrification}

This denotes a social condition in which more affluent people take possession of the assets of the less privileged people because of the envisaged potentials of the area under consideration. As gentrification occurs, lifestyles change and eviction of lower-income people becomes preponderant, a condition necessitated by the inability of relatively poor dwellers to afford new rent rates and cope with policies and other factors relating to high cost of living. As rurality continues to pave the way for urbanity occasioned by gentrification, investors and more affluent people are attracted. This is exemplified in places like Lekki and Ajah in Lagos where the aboriginal dwellers would gladly sell off their properties to high bidders, an area resulting from 
wealthier people buying housing property in a less prosperous community. Consequent to gentrification, the average income increases and average family size decreases in the community, which may result in the informal economic eviction of the lower income residents because of increased rents, house prices and property taxes. This type of population change reduces industrial land use when it is redeveloped for commerce and housing. In addition, new businesses, catering to a more affluent base of consumers, tend to move into formerly blighted areas, further increasing the appeal to more affluent migrants and decreasing the accessibility to less wealthy natives.

\section{Health and environmental issues}

It is pertinent to state that increasing health challenges is a critical issue in the analysis of city space. Most of the health hazards in the city are not dissociable from increasing level of pollution of all sorts. Constant emission of carbon monoxide and other unhealthy forms of biological and chemical substances into the atmosphere endangers the lives of people in both cities and their corresponding slums. Incomplete combustion of vehicular engines is not excusable in this regard. Similar to the problem of pollution is the issue of congestion which comes with poor ventilation. Poor ventilation in turn negatively impacts on the proper respiration of dwellers. As a result of the ever-increasing demand for housing, greed and inadequate planning, a good number of houses in Lagos are badly ventilated. Close to the problem of congestion is poor sanitation system which usually harbours increasing incidents of diseases like cholera, tuberculosis and sexually transmitted diseases among others. Very close to the problem of poor sanitation is the issue of poor or inadequate waste management schemes. Efficient refuse disposal requires huge logistics, expertise and financing. If left in the hands of private individuals alone, it is certain that abuse will become inevitable. However, it must be added that a redefinition of health by the World Health Organisation (WHO), which includes economic, social, physical, mental and emotional well-being of the people, reveals that stress and depression immensely contribute a great threat to healthy life in the city spaces. This explains why some people who are physically healthy attempt suicide probably because of stress at workplace or other forms of social or psycho-emotional frustrations (see, for example Ilesanmi 2010).

\section{Crime and urban social unrest}

Megacities around the world, be it in the developed or underdeveloped countries, have the same denominator of crime perpetrations and are places where social unrest often originates. Such unrest affects the rest of the world. The fabrics of urban life are such that druggists, fraudsters (especially advanced free fraudsters) and public fund looters take a shield under the pronounced stress and complexities of city life. Cities are more prone to terrorist or other forms of attacks than their counterpart rural centres. Fake drugs, fake currencies and other illicit products usually touch on Lagos harbour before diffusing to other parts of Nigeria as a result of propinquity to foreign and local industries. It is therefore sufficient to say that while city space sets the pace for social and economic development, it also conversely serves as the node of various criminal perpetrations.

\section{Issue of housing and homelessness}

Megacities often have significant numbers of homeless people. While megaslums often serve as the constituency of the majority of urban dwellers who could not afford the luxury of urban accommodation, the consequences of the imbalance is telling on both sides. Homelessness is subjective in meaning: while it could mean outright absence of shelter to some, it could mean lack of fitting shelter to others. One of the major disappointments rural escapees meet in city centres is absence of home. Little wonder why many Lagos residents maintain dual homes: (1) home for survival away from home and (2) real home (individual's original family residence) where emotional, familial and communal succour is guaranteed. The real home is where many Lagosians scramble to spend their special holidays like Christmas and New Year's Day. It should be reinstated that the scramble for more urban spaces engenders stress and congestion of urban residence, a big challenge constantly faced by Lagos megacity. Overpopulation causes untold overstretching of public amenities in Lagos as well and many other megacities around the world. It has been estimated by the World Bank that about $54 \%$ of Lagos residents (which is hovering around 15 million) live in slums. Unfortunately, the demand for urbanisation will continue to increase in the 21st century. It is, however, clear that this development will continue to have different implications for both social and economic development of the world at large (see Ilesanmi 2010).

\section{Conclusion and recommendations}

Without mincing words, it has been revealed in the above analysis that megacities create their own problems, chief of which is the ever-adjourning megaslum, especially in the underdeveloped countries of which Nigeria, homing Lagos, is preponderant. As enunciated in the article, there are overarching issues of sanitation, ill health, poor sanitation, tenure system, infrastructure, telecommunication, planning, crime, job crises, and down to infinitum, associated with living in slums. More problematic is how these issues impact megacities and the entire world from which they evolve. Megacities come with different living standards for different groups. While the arguments against pollution, depletion of ozone layers, poverty, traffic congestion, poor sanitations and criminal tendencies in the city space remain valid and plausible, the paradoxical realities of systematic exclusions and inclusions in cities must not be swept under the carpet. City life continues to be a mirage as demand for more cities is on the increase. Future forecasts reveal that rural spaces will continue to fade away. Consequently, we cannot but expect emergences of more city slums as slums are creations of cities and their complexities. Mayhap the view of the Marxists is right on this matter that capitalism creates its own detractors. 
In the same vein, having established the fact that the slum dwellers have their unique culture and economy sustained through group cohesion and resilient innovative practices, it is important to state at this juncture that slums have their own functional uniqueness as well as relevance to the everincreasing urban centres. Unequivocally, it is evident that that the proliferation of slums comes with both negative and positive implications for social, economic, judicial and political sustenance of cities in Nigeria, and hence the need to beam the searchlight on various possible ways to mitigate the challenges associated with slum dwelling and reduce inequality between the city dwellers and their counterparts in the slums whose survival is indispensable to the survival of the city. In the words of Michael J, as quoted in Jayaram (2010:12):

The global political economy has shifted into a period of intense restructuring and associated instability. Old spaces are being defiled, and new spaces are being defined, including those associated with deindustrialisation, environmentalism, reinvigorated nationalisms, diminished democracies, cyberspace, NIMBYism and minority-led social movements. Paralleling these shifts is the creation of different kinds of urbanism, characterised by edge cities, gated communities, and a global hierarchy of new 'world cities' that is a key to understanding the burgeoning geopolitical order. (p. 12)

\section{Recommendations}

- It must be realised that slum dwellers contribute immensely to the political, socioeconomic and geographical functionality of city space, and hence the need for government and the rich to take into cognisance their well-being which in turn would impact on the general peace in the city.

- Rather than demolishing slums, it will be more humane for policymakers to consider how to upgrade slums to better standard. This is simply because those in slums in Lagos, much as the case is in many other megacities, constitute the vast majority of the work force.

- The problem associated with insecure or unclear tenure in the slums should be properly addressed.

- There is also need to demystify illusions associated with urban life to prevent further incursion of nearly saturated megacities most of which suffer from over-stretched facilities.

- Proper environmental or urban planning, which is a missing link in Nigerian cities, must be addressed headlong.

- Working conditions in most companies in Lagos and other emerging cities cannot afford most of their staff a good living standard; this must also call for attention of the concerned parties.

- The resilient culture or nature of slum dwellers can be transformed to economic advantage in building a resilient city in Nigeria.

\section{Acknowledgements}

The research that led to this article received no funding from any source. We thank the anonymous reviewers and editor of this journal for comments on earlier drafts of the article. The comments ultimately improved the quality of this article.

\section{Competing interests}

The authors declare that they have no financial or personal relationships which may have inappropriately influenced them in writing this article.

\section{Authors' contributions}

O.A. was the project developer and leader. G.S.A. was responsible for literature and data gathering. Both authors made conceptual contributions and prepared the article.

\section{References}

Agbola, T. \& Agunbiade, E.M., 2009, 'Urbanization, slum development and security of tenure: The challenges of meeting millennium development goal 7 in Metropolitan Lagos, Nigeria', in A.A. de Sherbiniin, A. Rahman, J.C. Barbieri \& Y. Zhu (eds.), Urban population-environment dynamics in the developing world: Case studies and lessons learned, Committee for International Cooperation in National Research in Demography (CICRED), Paris, pp. 77-106. Viewed from http://www. populationenvironmentresearch.org/workshops.jsp\#W2007

Anthony, O., 2004, 'Urbanization', in G. Ritzer, Encyclopaedia of social theory, Sage, pp. 817-818.

Aworemi, J.R., Abdul-Azeez, I.A. \& Opoolo, N.A., 2011, 'An appraisal of the factors influencing rural-urban migration in some selected local government areas of Lagos State Nigeria', Journal of Sustainable Development 4(3), 136-141.

Bawaba, A., 2014, 'Urban slum in Lagos “Mega City”', viewed 06 February 2015, from http://search.proquest.com/docview/1476638430

Davis, K., 1955, 'The origin and growth of urbanization in the world', American Journa of Sociology 60(5), 429-437, viewed 21 January 2015, from www.jstor.org/ stable/2772530

Davis, M., 2006, Planet of slums, Verso Books, New York.

Ilesanmi, A.O., 2010, 'Urban sustainability in the context of Lagos Mega-City', Journal of Geography and Regional Planning 3(10), 240-252.

IRIN, 2006, IRIN. The Lagos Mega-city of Slums, viewed 01 August 2017, from http:// www.irinnews.org/news/2006/09/05/lagos-mega-city-slums

Jayaram, N., 2010, 'Revisiting the city: The contemporary relevance of urban sociology', paper delivered at Tata Institute of Social Sciences, Mumbai, India,
viewed 20 January 2015, from www.mmg.mpg.de/fileadmin/user_upload/pdf/ gcc/Jayaram.pdf

Kito, E., 2012, Before European Colonialism, was Africa essentially rural? Winter Publications (2012 Online edition), viewed 02 January 2015, from www. retrospectjournal.co.uk

Lavasani, S.M., 2013, 'An anthropological approach into the culture of slum living and students' educational status', European Journal of Experimental Biology 3(1), 705-708.

Lewis, O., 1966, 'The culture of poverty', American 215(4), 19-25.

Makinde, O.O., 2012, 'Urbanization, housing and environment: Megacities of Africa', International Journal of Development and Sustainability 1(3), 976-993.

Otite, O. \& Ogionwo, W., 2006, An introduction to sociological studies, 2nd edn., McMillan, Ibadan.

Portes, A., 1972, 'Rationality in slum: An essay on interpretive sociology', Comparative Studies in Society and History 14(3), viewed 16 January 2015, from http://www. jstor.org/stable/178217

Ritzer, G. \& Stepnisky, J., 2014, Sociological theory, 9th edn., McGraw Hill International, Singapore.

United Nations Department of Economic and Social Affairs, Population Division, 2014 World urbanization prospects: The 2014 revision, highlights (ST/ESA/SER.A/352), United Nations, New York.

UN Habitat, 2013, State of the world's cities 2012/2013, Prosperity of cities state of the world's cities (Series title), viewed 01 August 2017, from http://mirror. unhabitat.org/pmss/listltemDetails.aspx?publicationID=3387\&AspxAutoDetect CookieSupport $=1$

United Nations Economic Commission for Latin America and the Caribbean, 2012, Population, territory and sustainable development, LC/L.3474(CEP.2/3), United Nations, New York.

United Nations World Economic and Social Survey, 2013, Sustainable development challenges, UN Department of Economic and Social Affairs, United Nations, New York.

World Bank, 2013, Population living in slums, viewed 01 August 2017, from http:// data.worldbank.org/indicator/EN.POP.SLUM.UR.ZS 